\title{
Meiotic Investigation in Reciprocal Translocation Heterozygotes of Commelina benghalensis L. (Commelinaceae) Induced by Gamma Irradiations
}

\author{
Nilofar Shaikh ${ }^{1}$, Rakesh Chandra Verma ${ }^{1}$, Preeti Dass ${ }^{2}$ and Mushtaq Ahmad Khah ${ }^{3 *}$ \\ ${ }^{1}$ School of Studies in Botany, Vikram University, Ujjain-456010 (M.P.), India \\ ${ }^{2}$ School of Studies in Microbiology, Vikram University, Ujjain-456010 (M.P.), India \\ ${ }^{3}$ Department of Botany, Shri JJT University, Jhunjhunu-333001 (Rajasthan), India
}

Received March 7, 2020; accepted April 21, 2020

\begin{abstract}
Summary Commelina benghalensis L. is a diploid plant with $2 n=2 x=22$ median size chromosomes. Gamma irradiations $(10,15,20,25 \mathrm{kR})$ to $C$. benghalensis seeds induced 14 translocation heterozygotes. The translocation heterozygotes exhibited the formation of either a ring or a chain of four chromosomes in PMCs (ranged from 79.84 to $100 \%$ ). The translocation lines showed the preponderance of ring quadrivalents as compared to chain quadrivalents. After comparative analysis, the quadrivalents frequently displayed alternate disjunction (52.91\%) than adjacent disjunction (47.09\%). At anaphase I/II and telophase I/II, the translocation heterozygotes showed the presence of lagging chromosomes and chromatin bridges. Micronuclei were sometimes formed in tetrads. Heterozygous plants showed high pollen sterility (ranged from 21.30 to $81.82 \%$ ) due to the presence of adjacent orientation in quadrivalents and the cumulative effect of other meiotic irregularities. Also, pollen sterility showed a positive and significant correlation $\left(r^{2}=0.7285\right)$ with adjacent segregation of quadrivalents (ranged from 20.0 to $74.22 \%$ ) in translocation heterozygotes.
\end{abstract}

Keywords Commelina benghalensis, Gamma irradiation, Meiosis, Quadrivalent, Translocation heterozygote.

Commelina benghalensis L., the family Commelinaceae, is a diploid species with $2 n=2 x=22$ median size chromosomes. The plant is very beneficial from the medicinal point of view due to some very active compounds. Numerous compounds have been identified from the vegetative and flower parts including noctacosanol, $n$-triocotanol, stigma-sterol, compesterol and hydrocyanic acid (Jayvir et al. 2002). Phytochemical screening also revealed the presence of many secondary metabolites like phlorotannins, carbohydrates, tannins, glycosides, volatile oils, resins, balsams, flavonoids, and saponins (Jemilat et al. 2010). Presence of flavonoids, for example, indicates the plant might have an antioxidant, anti-allergic, anti-inflammatory, anti-microbial or anti-cancer activity (Kunle and Egharevba 2009). Also, C. benghalensis has an algetic action that proves the folkloric use in pain management (Hasan et al. 2010). Furthermore, recent studies show that $C$. benghalensis has many essential functional components for antibacterial activity (Khan et al. 2011).

Genetic variation is very important for improvement in the important features which are of medicinal value. Induced mutagenesis is an efficient method for the induction of morphological and genetic variability's in plants. Gamma irradiations have been efficiently utilized

\footnotetext{
* Corresponding author, e-mail: mushtaq.khah@yahoo.com DOI: $10.1508 /$ cytologia.85.213
}

from the past few decades in creating rapid genetic variability in some important traits. The gamma rays normally induce DNA lesions after producing free radicals which subsequently damages or modifies important gene products of plant cells (Khah and Verma 2017). Besides gross chromosomal aberrations, mutagens also cause point mutations in the individual genes leading to an increase in genetic variability in the segregating generations (Khah et al. 2018).

Reciprocal translocations arise by the exchange of broken segments of non-homologous chromosomes. Reciprocal translocations are usually identified by the presence of characteristic multivalent associations at metaphase I followed by partial pollen and ovule abortion (Khah and Verma 2020). Along with different aneuploids and other structural chromosomal aberrations, reciprocal translocation served as excellent cytogenetic tools for the identification and mapping of different linkage groups in plants (Sybenga 1996). It has also been involved successfully in transferring desirable traits (Sears 1956, Gustafsson 1965) and to generate different trisomics in a number of crop plants (Ashraf and Bassett 1987, Lakshmi and Nalini 1989, Talukdar 2009). The present study has been undertaken 1) to identify the translocation heterozygotes among the mutagenic populations 2) to study the meiotic behavior of these translocation heterozygotes by analyzing the configuration of interchange complexes and 3 ) to investigate the 
segregation pattern of chromosome complexes followed by their impact on pollen fertility.

\section{Materials and methods}

\section{Plant material and gamma ray treatment}

Healthy and fresh seeds of $C$. benghalensis L. were collected from the experimental field of School of Studies in Botany, Vikram University Ujjain, Madhya Pradesh, India. In total, 1000 seeds were subjected to various doses of gamma rays at Bhabha Atomic Research Center, Mumbai with the treatment doses 5, 10, $15,20,25,30,35,40$, and $50 \mathrm{kR}$. For each control and treatment dose, 100 seeds were then sown in separate pots with 10 seeds in each pot.

\section{Cytological preparation and meiotic analysis}

For meiotic studies, young floral buds were fixed in freshly prepared acetic acid-ethanol (1:3) fixative for at least $24 \mathrm{~h}$ and stored in a refrigerator until use. Slides were prepared using anther squash technique with $2 \%$ iron acetocarmine. Temporary slides were analyzed and suitable cells were photographed in an Olympus microscope. Observations were recorded on chromosome configurations at diakinesis and metaphase I with interchanged complex as a ring or chain associations. The interchanged complexes were assigned as alternate or adjacent segregations based on proposed configurations of Sybenga (1968). In alternate segregation, ring interchange complex appears like the symbol " 8 ", whereas a chain multiplex takes a zigzag orientation. However, open ring and linear chain configurations of multivalents are characteristic of adjacent disjunction. Pollen fertility was also estimated using $2 \%$ acetocarmine. Fertile pollen grains were recorded with stained nuclei whereas undersized and unstained pollen grains without nuclei
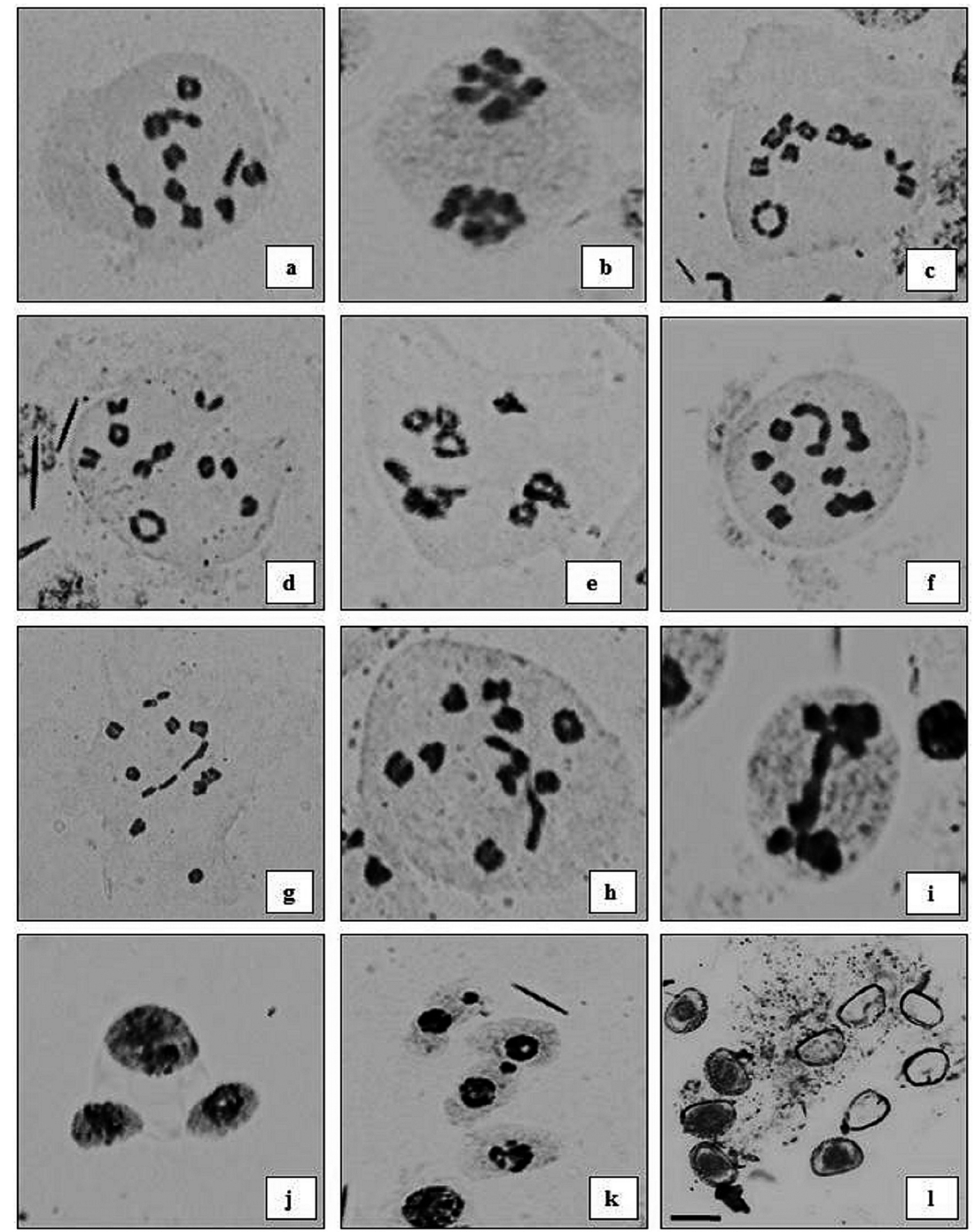

Fig. 1. Meiotic stages in control and translocation heterozygotes. a) Normal diakinesis with 11 bivalents $(2 n=22)$. b) Anaphase I with normal separation (11:11). c-d) One open ring quadrivalent with normal $9_{\mathrm{II}}$. e) One 8-shaped quadrivalent with normal $9_{\mathrm{II}}$ f $-\mathrm{g}$ ) One chain quadrivalent with normal $9_{\mathrm{II}}$. h) One chain quadrivalent (zig-zag shape) with normal $9_{\mathrm{II}}$. i) Chromatin bridge at anaphase I. j) Triad. k) Tetrad with micronuclei. 1) Fertile (stained) and sterile (unstained) pollens. Scale bar $=10 \mu \mathrm{m}$. 
were considered sterile.

\section{Results}

Meiosis was found normal in the PMCs of control plants which showed regular 11 bivalents at diakinesis and metaphase I (Fig. 1a). At anaphase I, chromosomes showed normal separation (Fig. 1b) followed by normal cytokinesis and regular formation of tetrads. Pollen fertility was normal in control populations (93.42\%).

In gamma irradiation populations, 14 plants (designated from CT-1 to CT-14) were found heterozygous for reciprocal translocations. Cytogenetic characterization of these plants showed ring and chain configurations of four chromosomes at diakinesis and metaphase I (Fig. 1c-h). The irradiation dose and percentage of PMCs showing the translocation complexes are shown in Table 1. The frequency of PMCs with interchange complex ranged from 79.84 to $100 \%$ (Table 1). The translocation heterozygotes, CT-1, CT-2, CT-4, CT-7-10, and CT-12-14, were characterized by the presence of $1_{\mathrm{IV}}+9_{\mathrm{II}}$ in all PMCs at metaphase I. However, the translocation heterozygotes, CT-3, CT-5, CT-6 and CT-11 showed the occurrence of interchange complexes in 86.99, 79.84, 87.84 and $91.14 \%$ of cells, respectively. Out of the total 14 translocation heterozygotes, six plants were isolated from $25 \mathrm{kR}$ M1 population while the four plants from $15 \mathrm{kR}$ populations. The other interchange heterozygotes were induced by $20 \mathrm{kR}$ (two plants) and $10 \mathrm{kR}$ irradiation doses (two plants).

Orientation behavior (alternate and adjacent) of interchange complexes was also studied by examining the meiotic configuration of translocation multiples at metaphase I (Table 2). A clear preponderance of rings (76.07\%) over the chains was observed, in which the mean percentage of open rings and bi-rings was approximately $32.85 \%(\mathrm{SD}= \pm 13.60)$ and $43.22 \%(\mathrm{~S}= \pm 16.11)$, respectively (Table 2). The overall chain configuration was found to be $23.93 \%$; though the occurrence of adjacently oriented chains showed prevalence (Mean=14.24; $\mathrm{SD}= \pm 10.82$ ) over the alternate chains (Mean $=9.69 \%$; $\mathrm{SD}= \pm 7.51)$. Thus, the overall percentage mean of the

Table 1. Irradiation dose, percentage of PMCs at metaphase I with translocation complex and pollen sterility of translocation heterozygotes of C. benghalensis.

\begin{tabular}{|c|c|c|c|c|c|}
\hline $\begin{array}{l}\text { Interchange } \\
\text { heterozygote }\end{array}$ & Irradiation dose $(\mathrm{kR})$ & PMCs analyzed & $\begin{array}{c}\text { PMCs showing } \\
\text { translocation complex }\end{array}$ & $\begin{array}{c}\text { PMCs showing } \\
\text { translocation } \\
\text { complex }(\%)\end{array}$ & Pollen sterility (\%) \\
\hline CT-1 & 10 & 142 & 142 & 100 & 37.98 \\
\hline CT-2 & 10 & 113 & 113 & 100 & 26.53 \\
\hline CT-3 & 15 & 146 & 127 & 86.99 & 46.75 \\
\hline CT-4 & 15 & 108 & 108 & 100 & 24.48 \\
\hline CT-5 & 15 & 129 & 103 & 79.84 & 55.20 \\
\hline CT-6 & 15 & 148 & 130 & 87.84 & 21.30 \\
\hline CT-7 & 20 & 104 & 104 & 100 & 32.58 \\
\hline CT-8 & 20 & 162 & 162 & 100 & 81.82 \\
\hline CT-9 & 25 & 122 & 122 & 100 & 34.19 \\
\hline CT-10 & 25 & 137 & 137 & 100 & 54.92 \\
\hline CT-11 & 25 & 158 & 144 & 91.14 & 47.76 \\
\hline CT-12 & 25 & 204 & 204 & 100 & 45.27 \\
\hline CT-13 & 25 & 119 & 119 & 100 & 51.85 \\
\hline CT-14 & 25 & 173 & 173 & 100 & 28.99 \\
\hline
\end{tabular}

Table 2. Chromosomal configuration and disjunction at metaphase $\mathrm{I}$ in the translocation heterozygotes of $C$. benghalensis.

\begin{tabular}{|c|c|c|c|c|c|c|c|}
\hline \multirow{2}{*}{$\begin{array}{l}\text { Interchange } \\
\text { heterozygote }\end{array}$} & \multirow{2}{*}{$\begin{array}{l}\text { Quadrivalents } \\
\text { analyzed }\end{array}$} & \multicolumn{2}{|c|}{ Ring of 4 chromosomes (\%) } & \multicolumn{2}{|c|}{ Chain of 4 chromosomes $(\%)$} & \multirow{2}{*}{$\begin{array}{c}\text { Alternate } \\
\text { disjunction (\%) }\end{array}$} & \multirow{2}{*}{$\begin{array}{c}\text { Adjacent } \\
\text { disjunction (\%) }\end{array}$} \\
\hline & & O-shaped & 8-shaped & C-shaped & Z-shaped & & \\
\hline CT-1 & 129 & 33.33 & 52.71 & 9.30 & 4.65 & 57.36 & 42.64 \\
\hline CT-2 & 97 & 7.22 & 50.52 & 13.40 & 28.87 & 79.38 & 20.62 \\
\hline CT-3 & 127 & 41.73 & 30.71 & 21.26 & 6.30 & 37.01 & 62.99 \\
\hline CT-4 & 99 & 15.15 & 72.73 & - & 12.12 & 84.85 & 15.15 \\
\hline CT-5 & 103 & 32.04 & 20.39 & 41.75 & 5.83 & 26.21 & 73.79 \\
\hline CT-6 & 130 & 20.00 & 63.85 & - & 16.15 & 80.00 & 20.00 \\
\hline CT-7 & 91 & 47.25 & 50.55 & 2.20 & - & 50.55 & 49.45 \\
\hline CT-8 & 128 & 49.22 & 16.41 & 25.00 & 9.38 & 25.78 & 74.22 \\
\hline СТ-9 & 99 & 26.26 & 48.48 & 8.08 & 17.17 & 65.66 & 34.34 \\
\hline CT-10 & 119 & 49.58 & 36.13 & 14.29 & - & 36.13 & 63.87 \\
\hline CT-11 & 144 & 18.75 & 52.78 & 19.44 & 9.03 & 61.81 & 38.19 \\
\hline CT-12 & 176 & 50.00 & 36.36 & 10.23 & 3.41 & 39.77 & 60.23 \\
\hline CT-13 & 110 & 40.91 & 21.82 & 21.82 & 15.45 & 37.27 & 62.73 \\
\hline CT-14 & 151 & 28.48 & 51.66 & 12.58 & 7.28 & 58.94 & 41.06 \\
\hline
\end{tabular}


Table 3. Frequency of various meiotic irregularities at anaphase I/II and telophase I/II in translocation heterozygotes of C. benghalensis.

\begin{tabular}{|c|c|c|c|c|c|c|}
\hline $\begin{array}{l}\text { Interchange } \\
\text { heterozygote }\end{array}$ & $\begin{array}{l}\text { Total cells } \\
\text { analyzed }\end{array}$ & Total abnormal cells & Laggards (\%) & Bridges (\%) & $\begin{array}{c}\text { Micronuclei } \\
(\%)\end{array}$ & $\begin{array}{c}\text { Abnormal tetrads } \\
(\%)\end{array}$ \\
\hline CT-1 & 113 & 26 & 7.9 & 6.2 & 3.5 & 5.3 \\
\hline CT-2 & 142 & 38 & 10.6 & 9.1 & 4.9 & 2.1 \\
\hline CT-3 & 107 & 13 & 3.7 & 2.8 & 3.7 & 1.9 \\
\hline CT-4 & 119 & 23 & 6.7 & 5.0 & 4.2 & 3.4 \\
\hline CT-5 & 105 & 19 & 5.7 & 4.8 & 3.8 & 3.8 \\
\hline CT-6 & 103 & 18 & 5.8 & 3.9 & 2.9 & 4.8 \\
\hline CT-7 & 148 & 43 & 12.8 & 8.1 & 4.0 & 4.0 \\
\hline CT-8 & 137 & 31 & 9.5 & 8.0 & 2.9 & 2.2 \\
\hline CT-9 & 122 & 24 & 5.7 & 7.4 & 2.4 & 4.1 \\
\hline CT-10 & 129 & 38 & 10.8 & 8.5 & 6.2 & 3.9 \\
\hline CT-11 & 118 & 24 & 9.3 & 5.9 & 1.7 & 3.4 \\
\hline CT-12 & 107 & 18 & 4.7 & 6.5 & 3.7 & 1.9 \\
\hline CT-13 & 143 & 37 & 9.8 & 8.4 & 4.9 & 2.8 \\
\hline CT-14 & 153 & 44 & 13.7 & 9.1 & 2.0 & 3.9 \\
\hline
\end{tabular}

incidence of adjacent and alternate orientations was found as $47.09 \%$ and $52.91 \%$, respectively. The meiotic disjunction of interchange chromosomes is very critical as it regulates the fate of the cell. In this study, out of total 1703 quadrivalents analyzed, 889 (52.20\%) showed alternate type of segregation and 814 (47.80\%) showed adjacent segregation. Among different chromosomal associations, ring quadrivalents mostly tend to orient in alternate types rather than adjacent types. Among 1703 quadrivalents, 1303 (76.51\%) showed ring configuration at metaphase in which 732 quadrivalents (56.18\%) displayed alternate disjunction and 571 quadrivalents (43.82\%) possessed adjacent segregation.

The translocation heterozygotes displayed various meiotic anomalies at anaphase I/II and telophase I/II (Table 3, Fig. 1i-k). The anomalies included lagging chromosomes $($ mean $=8.34$; range $=3.7-13.7 \%$ ) and chromatin bridges $($ mean $=6.69$; range $=3.9-9.1 \%)$ and. The lagging chromosomes were found in the form of univalents or as whole bivalents. Abnormal cytokinesis led to the formation of dyads, triads, pentads, and hexads in translocation heterozygotes (Fig. 1j). The tetrads also exhibited the presence of micronuclei (Fig. 1k) among interchange heterozygotes. The number of micronuclei within tetrads ranged from one to four, but the maximum exhibited one or two micronuclei. The pollen fertility was also reduced in translocation heterozygotes (Table 1) which ranged from 21.30 to $81.82 \%$ in CT-12 and CT-7, respectively. The translocation heterozygotes showed stunned growth with weak stem and high sterility. Most of the heterozygotes displayed no seed set.

\section{Discussion}

Interchanges, involving the exchange of chromosome segments, have massive importance as they signify a model of surveying genetic and cytological changes, and provide novel gene combinations by breaking undesirable associations. Gamma irradiations have been successfully employed for creating chromosomal interchanges in a number of plant species (Verma and Raina 1990, Verma and Goyal 2012, Verma and Shrivastava 2014, Khah and Verma 2017, 2020). These interchange heterozygotes are a significant tool for chromosome manipulation and sustainable interchange heterozygotes have great significance in breeding programs of the plant.

In the present study, 14 translocation heterozygotes were identified by the presence of ring and chain configurations of four chromosomes at diakinesis and metaphase I. In all translocation heterozygotes observed, the number of ring quadrivalents was higher than that of the chain quadrivalents. Various factors that affect the meiotic configuration of interchange multiples include the morphology of translocated chromosomes, the position of the translocated part, position and number of the chiasma, degree of chiasma terminalization, and arm ratio (Sybenga 1968, Verma and Raina 1990, Khah and Verma 2020). Interchange chromosomes with break sites near centromere and more or less equal in length causes a high incidence of ring configuration. However, shorter the interchanged segments the more likely it fails to pair with the homologous segment, and therefore, chain formation takes place. Also, chiasma failure may produce an open-chain association of a multivalent instead of a ring. In the present study, the high prevalence of ring quadrivalents in translocation heterozygotes seems to be due to a larger length of interchanged segments as well as stable chiasma associations in all the chromosome arms.

The translocation heterozygotes also showed a reduction in pollen fertility. The orientation of translocation multiples at metaphase I has a great bearing on the fertility of interchange heterozygote (Verma and Raina 1990). Alternate I and II segregation give rise to fertile gametes while adjacent I and II give rise to nonviable duplication and deficiency gametes. When these two types of segregations are of equal frequency, the result is semi-sterility. The difficulty of the quadrivalents to segregate accurately at anaphase I/II or telophase I/II 


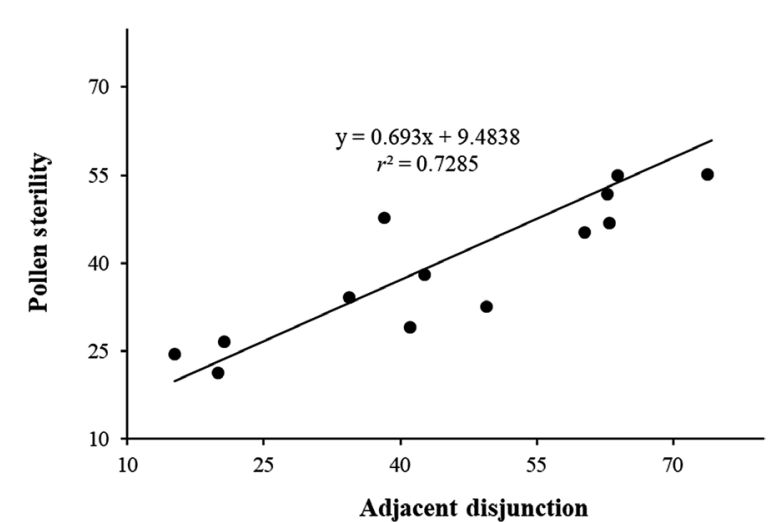

Fig. 2. Correlation between adjacent disjunction of interchange multiples and sterility of pollen grains.

creates various abnormalities which include laggards, bridges, micronuclei and others. The cumulative effects of these abnormalities also contribute to pollen sterility later in translocation heterozygotes. A high degree of pollen sterility observed in both semi-sterile translocation heterozygotes can be attributed not only to anaphase and telophase abnormalities but also to adjacent types of disjunctions $\left(r^{2}=0.7285\right.$, Fig. 2). If such translocation lines are established by removing their sterility barrier, novel gene combinations are expected to be induced through trisomics isolation which could be beneficial in future cytogenetic programs.

\section{References}

Ashraf, M. and Bassett, M. J. 1987. Five primary trisomics from translocation heterozygote progenies in common bean, Phaseolus vulgaris L. Theor. Appl. Genet. 74: 346-360.

Gustafsson, A. 1965. Characteristics and Rate of High Productive Mutants in Diploid Barley. The Use of Induced Mutations in Plant Breeding. FAO/IAEA Technical Meeting, Rome. pp. 323-337.

Hasan, S. M., Hossain, M., Akter, R., Jamila, M. and Mazumber, M. E. 2010. Analgesic activity of the different fractions of the aerial parts of Commelina benghalensis Linn. Int. J. Pharm. 6: 63-67. Jayvir, A., Minoo, P., Gauri, B. and Ripal, K. 2002. Natural Heals: A Glossary of Selected Indigenous Medicinal Plant of India 2nd Edn. SRIST Innovations, Ahmadabad.

Jemilat, I., Chioma, A. V. and Omoregie, H. 2010. Pharmacognostic and phytochemical analysis of Commelina benghalensis L. Ethnobot. Leaflet 14: 610-615.

Khan, M. A. A., Islam, M. T., Rahman, M. A. and Ahsan, Q. 2011. Antibacterial activity of different fractions of Commelina benghalensis L. Pharma. Sinica 2: 320-326.

Khah, M. A. and Verma, R. C. 2017. Cytological characterization of induced multiple translocation heterozygote in pearl millet (Pennisetum glaucum L.). Cytologia 82: 443-447.

Khah, M. A. and Verma, R. C. 2020. Gamma irradiation induced multiple chromosome interchanges in Hordeum vulgare L. (Poaceae): Meiotic characterization and their implications on pollen fertility. Nucleus 63: 151-157.

Khah, M. A., Verma, R. C. and Purbiya, R. 2018. Assessment of meiotic abnormalities induced by gamma irradiations in Zea mays $\mathrm{L}$. (Poaceae). Chromosome Sci. 21: 75-80.

Kunle, O. F. and Egharevba, H. O. 2009. Preliminary studies on Vernonia ambigua: Phytochemistry and antimicrobial screening of whole plant. Ethnobot. Leaflets 13: 1216-122.

Lakshmi, N. and Nalini, P. 1989. Tertiary trisomic in Capsicim annuum L. Cytologia 54: 395-399.

Sears, E. R. 1956. The transfer of leaf rust resistance from Aegilops umbellulata to wheat. In: Genetics in Plant Breeding, Brookhaven Symp. Biol. Brookhaven National Laboratory, New York. pp. $1-22$.

Sybenga, J. 1968. Orientation of interchange multiples in Secale cereal. Heredity 23: 73-79.

Sybenga, J. 1996. Aneuploid and other cytological tester sets in rye. Euphytica 89: 143-151.

Talukdar, D. 2009. Dwarf mutations in grass pea (Lathyrus sativus L.): Origin, morphology, inheritance and linkage studies. J. Genet. 88: 165-175.

Verma, R. C. and Goyal, S. 2012. Induced reciprocal translocation in Pisum sativum L. Cytologia 77: 485-489.

Verma, R. C. and Raina, S. N. 1990. Cytogenetics of Crotalaria IV. Induced translocation lines in C. juncea. Nucleus 33: 11-14.

Verma, R. C. and Shrivastava, P. 2014. Radiation-induced reciprocal translocations in safflower (Carthamus tinctorius L.). Cytologia 79: $541-545$. 